\title{
Phosphorus Based Ceramics for Positive Electrode Synthesis and Characterization
}

\author{
Diouma Kobor*, Abdou Kadri Diallo, Modou Tine \\ Laboratoire de Chimie et de Physique des Matériaux (LCPM), Département de Physique, University Assane \\ Seck of Ziguinchor, Ziguinchor, Senegal \\ Email: ${ }^{\text {dkobor@univ-zig.sn }}$
}

Received 24 April 2014; revised 21 May 2014; accepted 15 June 2014

Copyright (C) 2014 by authors and Scientific Research Publishing Inc.

This work is licensed under the Creative Commons Attribution International License (CC BY). http://creativecommons.org/licenses/by/4.0/

(c) (i) Open Access

\section{Abstract}

Historically, the $\mathrm{LiCoO}_{2}$ is the most used as active material for battery positive electrode because of its great potential $(3.7-4.2 \mathrm{~V})$, its interesting specific capacity $\left(150 \mathrm{~mA} \cdot \mathrm{h}^{-1} \mathrm{~g}^{-1}\right)$ and its excellent life cycle [1]. However, its toxicity, the cobalt cost and its structural instability oriented research towards new materials more stable that can replace it. In another context, hybrid, electrical vehicles and communication (computers and mobile phones...) have increased the scientific and technological research for new materials capable of storing and return energy through a system called accumulator. And research has identified the phosphate olivine structure as the most prolific ceramic material for positive electrode. $\mathrm{LiFePO}_{4}$ is a promising cathode material for Lithium-ion batteries. It provides high thermal stability and is synthesized using low cost materials. Unfortunately $\mathrm{LiFePO}_{4}$ suffers from a low electrical conductivity, which is harmful to its electrochemical performance. Decreasing the particle size, coating the particles with carbon or doping with metal atoms can increase the conductivity of the material. In this paper, we present the synthesis, physico-chemical and electrical characterization of lithium and iron doped Al-phosphorrus-based ceramic. The NPK Fertiliser was used as Al and phosphorus precursors. The powder XRD spectrum shows a possible presence of $\mathrm{LiFePO}_{4}$ and $\mathrm{Fe}_{2}(\mathrm{PO})_{3}$ in the heterostructure. An important quantity of $\mathrm{Al}$ is found by EDX spectra which supposed that the most important based atom is Aluminum and not Phosphorus. This can explain the increase of the conductivity value is $10^{2}$ times more important than those found in the literature for $\mathrm{LiFePO}_{4}$.

\section{Keywords}

Characterization, X-Ray Diffraction, EDX, Ceramic, Positive Electrode

\footnotetext{
${ }^{*}$ Corresponding author.
} 


\section{Introduction}

For decades most of the research for positive electrode technological achievements was devoted to transition metals oxides such as $\mathrm{Li}_{x} \mathrm{MO}_{2}(\mathrm{M}=\mathrm{Co}, \mathrm{Ni}, \mathrm{Mn})$. Thus the compounds synthesized from transition metals and poly anions $\left(\mathrm{XO}_{4}\right)^{n-}$ have been actively investigated during the past decade. Polyanions groups such as $\left(\mathrm{PO}_{4}\right)^{3-}$ have many advantages such as:

- Structural stability (essential for security and element cycling);

- The chemical nature and their association with redox couple of the transition metal that gives high potential values of those oxides;

- the possibility of varying the crystal structures [2].

Trad K. et al. [3] demonstrated that the $\mathrm{LiFePO}_{4}$ phase exhibits interesting electrochemical performances. And various studies have shown that several factors such as the synthesis method, particle morphology, and electrical conductivity of the material are very important for achieving good electrochemical performances in lithium battery. In this work we try to synthesize phosphate based ceramic and increase its conductivity by using a very low cost and accessible product (NPK fertilizers) as the synthesis precursors and as the Al dopant.

\section{Experimental Procedure}

In this section, the paper will focus on the different steps of the synthesis of a phosphorus base ceramic with NPK fertilizer, lithium chloride and iron chloride (3) as Li and Fe precursors. The structural and electrical characterization of the obtained materials at room temperature and high temperature will also be discussed.

\subsection{Synthesis}

NPK fertilizer with $20 \%$ of $\mathrm{P}_{2} \mathrm{O}_{5}$ and chemical powders $\mathrm{LiCl}(99 \%)$ and $\mathrm{FeCl}_{3} \cdot 6 \mathrm{H}_{2} \mathrm{O}(99 \%)$ were used as starting materials. The NPK contains also non negligible quantity of $\mathrm{Al}, \mathrm{K}$ and $\mathrm{N}$ considered here as dopants. The desired mol ratio $\mathrm{Li} / \mathrm{Fe} / \mathrm{PO}_{4}$ is $1: 1: 1 / 2$. The ceramics were synthesized using the solide state technique. Powders were mixed in alcohol, ground and calcined at $400^{\circ} \mathrm{C}$ for 2 hours in order to synthesize the $\mathrm{LiFePO}_{4}$ based ceramics using a muffle furnace $\mathrm{K} 114$ of $\mathrm{GmBH}$. The resulting powder mixture was mixed with 10 wt\% polyvinyl alcohol (PVA) solution, and was pressed to prepare pellets with $13 \mathrm{~mm}$ of diameter and $1.2 \mathrm{~mm}$ of thickness with a $80 \mathrm{MPa}$ uniaxial stress. The pellets were sintered at $800^{\circ} \mathrm{C}$ for 4 hours in a sealed crucible (Figure 1).
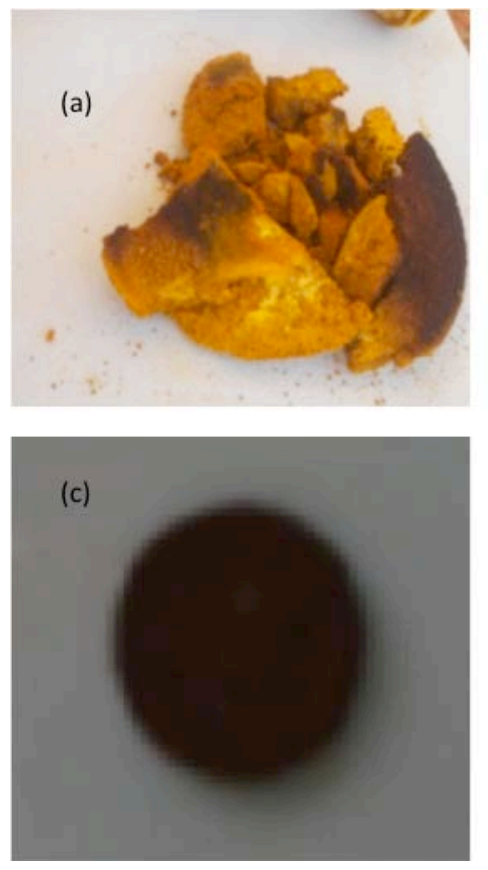

Figure 1. (a) $400^{\circ} \mathrm{C}$ calcined powder and (b) $800^{\circ} \mathrm{C}$ calcined powder (c) pellet from the $800^{\circ} \mathrm{C}$ calcined powder (d) pellet after metalization.
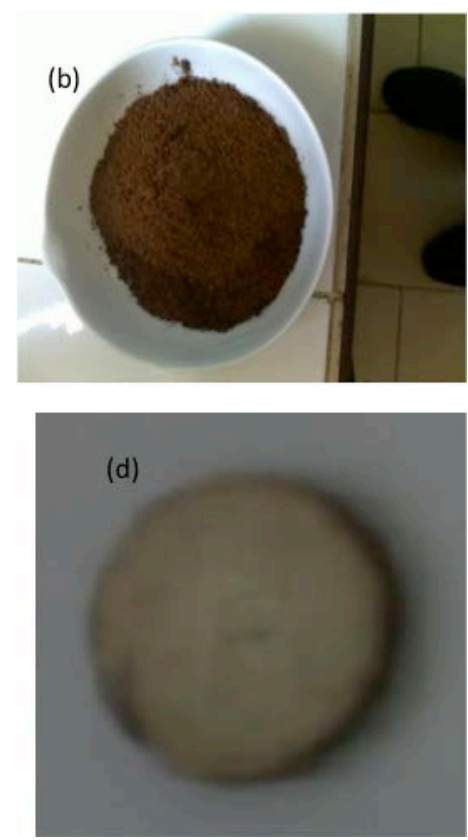


\subsection{Structural Analysis}

X-Ray powder Diffraction was performed on synthesized powder with the help of a SIEMENS diffractometer equiped with sol-X detector using a monochromatic selecting CuK $\alpha$ radiation $(\lambda=1.5418 \AA$ ).

To determine the actual chemical composition of the ceramic, a basic chemical microanalysis by EDX (Energy Dispersive X-ray spectrometry) method, called dispersive energy analysis, was performed. For this we used a SEM Cambridge S260.

The thermal expansion can be followed during a programmed heating cycle of the sample. Dilatometric analysis allows easy phases change identification, allotropic transformations identification and reactions in the solid state which take place during the heating and often phenomena accompanied by a significant increase in volume. These measures were performed by the use of a TMA Setsys Evolution Setaram dilatometer.

\subsection{Electrical Measurement}

To study the electrical behavior of pellets, prepared from the synthesized ceramic powder, the stationary current measurement was performed. The pellet faces were metallized with silver paste using the screen printing method. For this characterization technique, the sample is mounted in a series circuit with a direct current generator. Using a multimeter, the current through the sample is measured. The applied voltage varies from 0 to $10 \mathrm{~V}$ in steps of $0.5 \mathrm{~V}$. The $I_{\text {stationary }}$-voltage characteristic is studied at different temperatures. The advantage of this technique relies on the determination of the pellet ohmic behavior. In fact, this behavior is the grains effect on the electrical conductivity of the material. The sample resistance $R_{\mathrm{e}}$ is given by the inverse of the graph slope $I=f(U)$ that is generally linear. The sample conductivity is deduced from its geometric parameters and its resistance by the formula:

$$
R_{\mathrm{e}}=\frac{\mathrm{e}}{\sigma \mathrm{s}}
$$

With e the thickness, $S$ the surface and $\sigma$ the electrical conductivity of the sample.

\section{Results and Discussion}

\section{Structural Analysis}

Figure 2(a) shows the X-ray diffraction pattern for the sample sythesized with the NPK fertilzer. The overall pattern (with the presence of various sharp peaks) indicates a relatively high degree of crystallinity. Diffraction peaks were identified as belonging to two phosphorus based crystalline compounds: iron phosphate, $\mathrm{FePO}_{4}$ and lithiumiron phosphate, $\mathrm{LiFePO}_{4}$ — "triphylite" [4]. Indeed, the presence of peaks at $21^{\circ}, 26^{\circ}$ and $37^{\circ}$ indicate the presence of $\mathrm{FePO}_{4}$ component as well as the presence of peaks at $17^{\circ}, 26^{\circ}$ and $37^{\circ}$ confirms the presence of Li$\mathrm{FePO}_{4}$ in the ceramic. However, we note other peaks, showing the possible presence of unidentified compounds which certainly came from the fertilizer chemical elements (N, K, Si, Al, etc). For us the presence of potassium should not have significant influence on the conductivity properties as belonging to the same chemical family as lithium and therefore having the same properties. As against, the presence of nitrogen would be considered as a dopant that could be beneficial.

The results of EDX analysis made for the samples (Figure 3) are consistent with the fact that the ceramic is based on a lithium iron phosphate, with $\mathrm{Al}, \mathrm{S}$ and $\mathrm{Ca}$ atoms as dopants, making it a compound of possible general formula $\left(\mathrm{Li}_{x} \mathrm{~K}_{1-x} \mathrm{Fe}_{y} \mathrm{Al}_{1-y} \mathrm{P}_{z} \mathrm{O}_{n}\right)$ with the presence of $\mathrm{Ca}$ and $\mathrm{S}$ impurities. The aluminium peak is the sharpest. This could be explained by the presence of an aluminum rate larger than the other compounds. Thus, the ceramic may be rather considered aluminum based materials $\left(\mathrm{Li}_{x} \mathrm{~K}_{1-x} \mathrm{Al}_{y} \mathrm{Fe}_{1-y} \mathrm{P}_{z} \mathrm{O}_{n}\right)$.

The thermal expansion of the samples was performed with a thermal cycle of $5^{\circ} \mathrm{C} / \mathrm{min}$ and rising to $20^{\circ} \mathrm{C} / \mathrm{min}$ without any plateau.

Figure 4 shows the sample behavior under a cycle heat treatment from room temperature to $900^{\circ} \mathrm{C}$. The first phase corresponds to an expansion of the material lattice parameter (Figure 4(a)) which starts from the ambient to $400^{\circ} \mathrm{C}$. This behavior can be explained by the natural behavior (thermal expansion) of any heated material. The second phase is from $400^{\circ} \mathrm{C}$ to around $800^{\circ} \mathrm{C}$. This phase corresponds to contractions that are due to different physical phenomena namely dehydration and optionally some chemical compounds extrusion. Our ceramic densification begins only around $820^{\circ} \mathrm{C}$. From $820^{\circ} \mathrm{C}$, the curve shows a significant shrinkage which can be at 

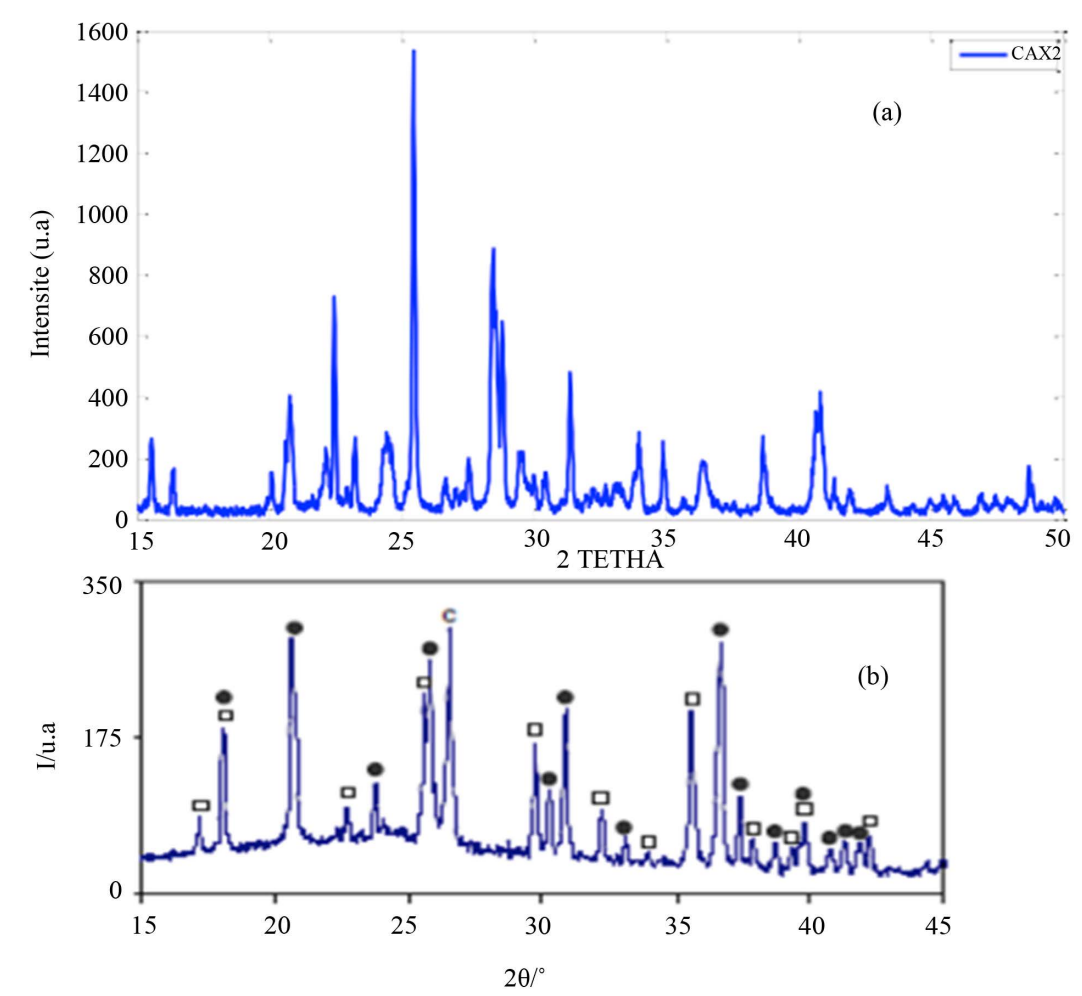

Figure 2. X-ray powder diffraction pattern for (a) the as synthesized ceramic; (b) $\mathrm{FePO}_{4}(\bullet)$ and $\mathrm{LiFePO}_{4}(\square)[4]$.

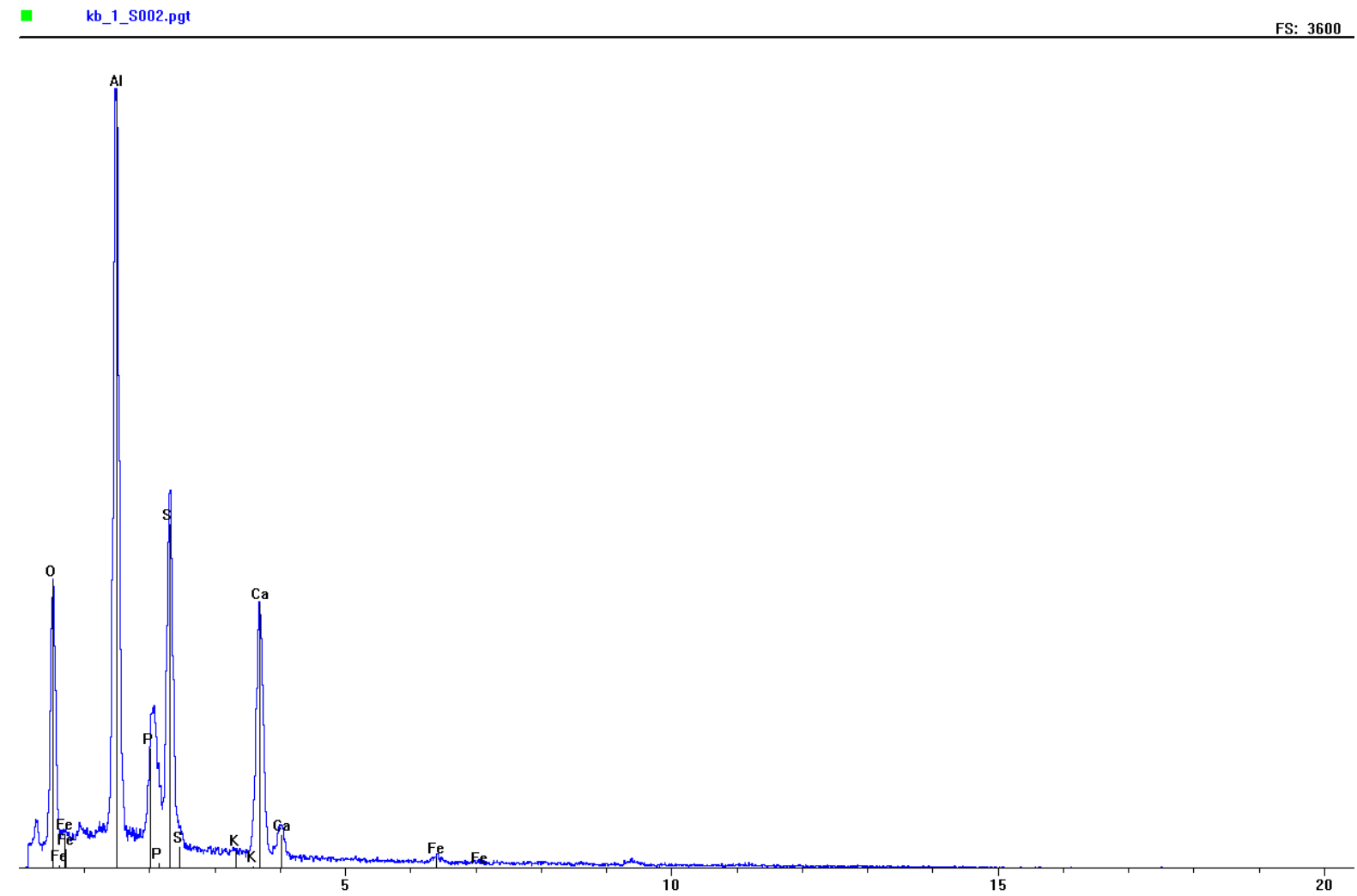

Figure 3. EDX spectra corresponding to the synthesized sample analysis. 

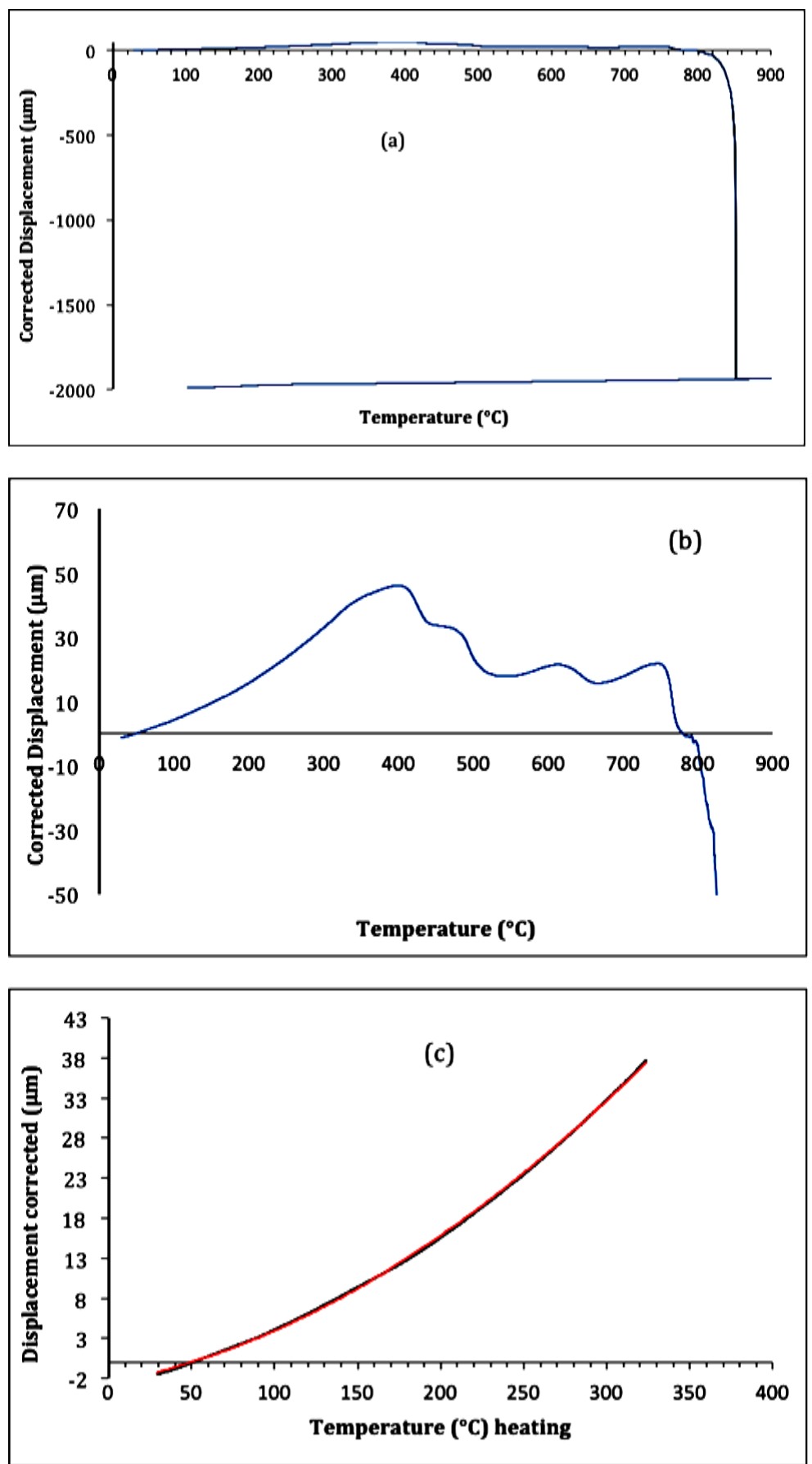

Figure 4. The thermal dilatation of the synthesized ceramic (a) global view; (b) a zoom between $100^{\circ} \mathrm{C}$ to $800^{\circ} \mathrm{C}$ and (c) the thermal expansion model.

tributed to glass transition of the material and thus the presence of a new and more stable crystal structure.

Figure 4(b) shows a more detailed view of our ceramic behavior between room temperature and $800^{\circ} \mathrm{C}$. Four physical phenomena (shrinkages) can be observed. Between $400^{\circ} \mathrm{C}$ to $450^{\circ} \mathrm{C}$, heat treatment accelerates the creation of structural defects which is characterized by a contraction of the lattice due to the iron components extrusion. This phenomenon is observed by Julien et al. [5] who detected the presence of $\mathrm{Fe}_{2} \mathrm{O}_{3}$ and $\mathrm{Li}_{3} \mathrm{Fe}_{2}\left(\mathrm{PO}_{4}\right)_{3}$. Other shrinkagesat $460^{\circ} \mathrm{C}, 600^{\circ} \mathrm{C}$ and $725^{\circ} \mathrm{C}$ could be explained by the presence of other chemical impurities (N, $\mathrm{K}, \mathrm{Al}$, etc.) observed on EDX spectra (Figure 3). 
Figure 4(c) shows a modeling of the thermal behavior of our ceramic between $30^{\circ} \mathrm{C}$ and $400^{\circ} \mathrm{C}$. It is noted that the thermal expansion is a quadratic function of the temperature for this range (before the shrinkage). This relation can be written as:

$$
\Delta l-\Delta l_{0}=a T^{2}+b T
$$

with $a=3 \times 10^{-4} \mu \mathrm{m} \cdot{ }^{\circ} \mathrm{C}^{-2}, \quad b=4 \times 10^{-2} \mu \mathrm{m} \cdot{ }^{\circ} \mathrm{C}^{-1}$ and $\Delta l_{0}=-2.72 \mu \mathrm{m}$.

The thermal expansion coefficient is determined for the temperature range between 30 and $150^{\circ} \mathrm{C}$ at the heating rate and is equal to $8.84 \times 10^{-8} \mathrm{~K}^{-1}$. This value is $10^{2}$ times more important compared to values often found in the literature $\left(1.9 \times 10^{-6} \mathrm{~K}^{-1}\right)$ [6]. This low thermal expansion coefficient, compared to $\mathrm{LiFePO}_{4}$, is an advantage for using this material under extrem conditions.

Figure 5 shows the I-V curves under different temperatures $\left(33^{\circ} \mathrm{C}, 55^{\circ} \mathrm{C}, 70^{\circ} \mathrm{C}\right.$ and $\left.83^{\circ} \mathrm{C}\right)$. The observed linearity of the curve $\left(T=33^{\circ} \mathrm{C}\right)$ reflects the ohmic behavior of the material under these temperatures. What could be explained by the fact that in this temperature, the conductivity is dominated by electrons movment. However the resistive or ohmic character of the material disappears when the temperature is increased $\left(55^{\circ} \mathrm{C}\right.$, $70^{\circ} \mathrm{C}$ and $83^{\circ} \mathrm{C}$ ). In fact the vibrational contribution of atoms, at temperature over $33^{\circ} \mathrm{C}$, gives rise to ions which will contribute to the conduction phenomenon. Also when the material is subjected to a temperature increase, the space charges created by the impurities and defects increase the current through the material. This phenomenon, gradually, increases the effect of the ionic conduction which would dominate at high temperatures.

So we can conclude that at low temperature, conductivity is dominated by the electronic conduction while at high temperature the ionic one becomes important. This explains the non-linearity of these curves as soon as the temperature increases.

We modelized the DC current variation as a function of the voltage by a quadratic equation

$$
I=\alpha V^{2}+\beta V+\gamma
$$

The constants $\alpha, \beta$ and $\gamma$ values are summarized in the Table 1 . At low temperature $\alpha=0$.

These conductivity values obtained using the (Equation (1)) (Table 1) are larger than those usually obtained $\left(\sim 10^{-9} \mathrm{~S} \cdot \mathrm{cm}^{-1}\right.$ in the case of intrinsic $\left.\mathrm{LiFePO}_{4}\right)[7]$.

In most semiconductors or insulating materials, the conductivity is generally thermally activated according to the Arrhenius law:

$$
\begin{gathered}
\sigma=A \mathrm{e}^{-\Delta E / k T} \\
\text { so, } \log (\sigma)=\log (A)-\frac{\Delta E}{k T}
\end{gathered}
$$

This relation (Equation (5)) permits to calculate the activation energy of this material at this temperature

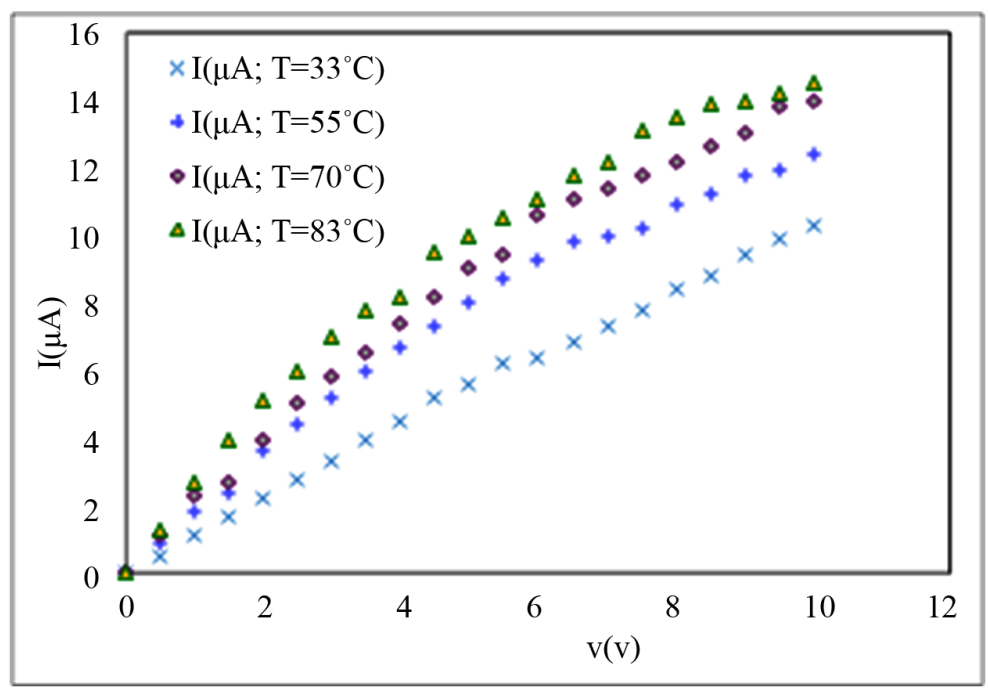

Figure 5. I-Vcurves for different temperatures $\left(33^{\circ} \mathrm{C}, 55^{\circ} \mathrm{C}, 70^{\circ} \mathrm{C}\right.$ and $\left.83^{\circ} \mathrm{C}\right)$. 
range. Its value $(0.17 \mathrm{eV})$ is less important than those found in literature $(0.31-0.5 \mathrm{eV})$ for $\mathrm{LiFePO}_{4}$ materials [5]. The activation energies calculated at about $300 \mathrm{~K}$ decreases with increasing $\mathrm{LiFePO}_{4}$ synthesis temperature according to Maccario [8]. The presence of many impurities (K, Si, Li, Fe, etc) can explain this difference and the weakness of the activation energy due to the ionic conduction. The result was expected because the value of ourceramic conductivity is $10^{2}$ times higher than that of $\mathrm{LiFePO}_{4}$.

The curve behaviour in the Figure 6 is known under the name of Universal Dynamic Response (UDR) [9], in which the AC conductivity versus frequencies obeys the following law:

$$
\sigma_{\mathrm{AC}}(\omega)=A \omega^{n}
$$

where $A$ and $n$ are constants at a given temperature. $n$ is a measurement of the electric relaxational behavior, usually with a value of: $0 \leq n \leq 1$ [9]. Many "elementary" hops of the mobile ions are seen (per unit time) within a sufficiently short time window, corresponding to the plateau of the conductivity. Eventually, however, only a small fraction of them prove "successful", contributing to the DC conductivity and thus constituting the long-time "random" hopping dynamics of the ions. In glassy and structurally disordered crystalline electrolytes, the "elementary" hops as well as the fraction of "successful" ones are usually Arrhenius activated [10]. The particularity of this material is the fact that such behavior is observed in dielectric or insulating matreials at high frequencies while it is observed here at relatively low frequencies $\left(<10^{4} \mathrm{~Hz}\right)$. We used the Equation (4) to determine the values of $A$ and $n$ with $A=1.96 \times 10^{-19}(\Omega \cdot \mathrm{m})^{-1} \cdot \mathrm{rd}^{n} \cdot \mathrm{s}^{-n}, n=0.46$ and $\sigma_{\mathrm{DC}} \approx 1.40 \times 10^{-8}(\Omega \cdot \mathrm{m})^{-1}$ found according, at ambient temperature, the following equation:

$$
\sigma_{\mathrm{AC}}(\omega)=\sigma_{\mathrm{DC}}+A \omega^{n}
$$

For Sidebottom [11], the value of the exponent $\mathrm{n}$ is depending to the dimension order in the conducting space.

The value of the $\sigma_{\mathrm{DC}}$ conductivity from the UDR curve is appreciably 10 times less important that those found in the DC conductivity measurement.

\begin{tabular}{|c|c|c|c|c|}
\hline \multicolumn{5}{|c|}{ Constants $\left(10^{-6}\right)$} \\
\hline$T \quad\left({ }^{\circ} \mathrm{C}\right)$ & $\alpha$ & $\beta$ & $\gamma$ & $\sigma \quad\left(\mathrm{S} \cdot \mathrm{cm}^{-1}\right)$ \\
\hline 33 & 0 & 1.027 & 0.203 & $1.31 \times 10^{-7}$ \\
\hline 55 & -0.076 & 1.992 & -0.103 & $1.94 \times 10^{-7}$ \\
\hline 70 & -0.079 & 2.180 & -0.035 & $2.16 \times 10^{-7}$ \\
\hline 83 & -0.108 & 2.496 & 0.255 & $2.86 \times 10^{-7}$ \\
\hline
\end{tabular}

Table 1. The physico-chemical and electrical coefficients of the as synthesized ceramic.

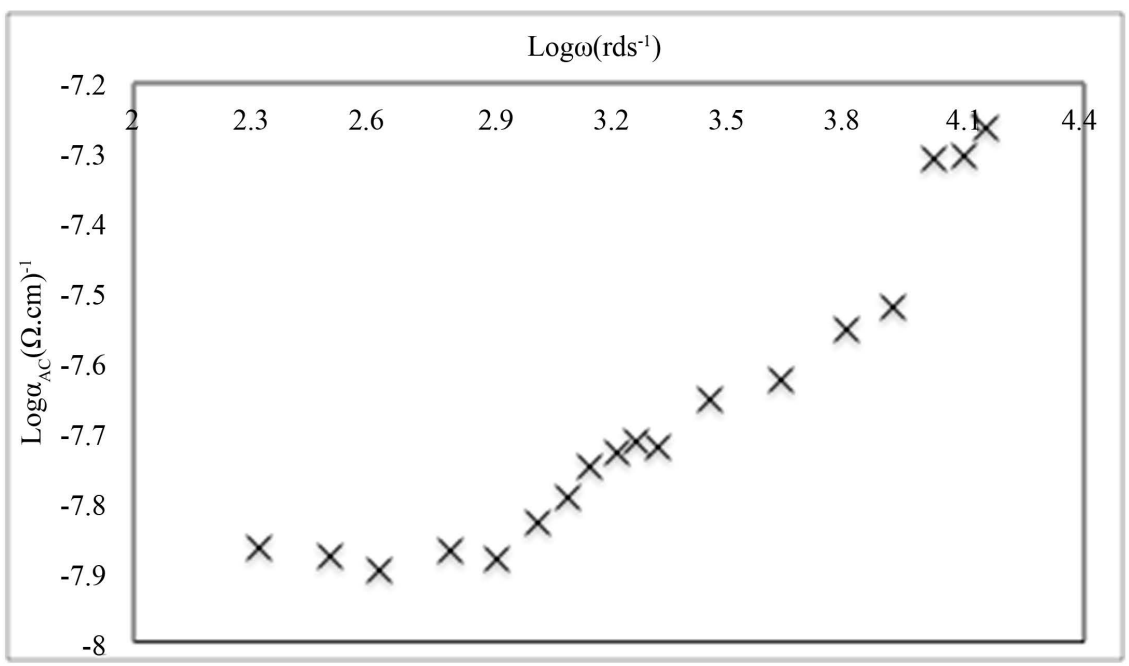

Figure 6. AC conductivity behavior at low frequencies. 


\section{Conclusions}

In this work, we have shown that it is possible to use a very low cost product as (NPK fertilizer) for a $\mathrm{LiFePO}_{4}$ based ceramics for accumulators. The physicochemical properties by XRD and EDX showed that this material is mainly composed of aluminum, phosphorus, calcium and impurities considered as dopants (Fe, K, Li etc.). A chemical component as $\mathrm{Li}_{x} \mathrm{~K}_{1-x} \mathrm{Al}_{y} \mathrm{Fe}_{1-y} \mathrm{P}_{z} \mathrm{O}_{n}$ is proposed as synthesized ceramic. This material has yielded interesting results for the electrical conductivity $\left(10^{2}\right.$ times greater than that of $\left.\mathrm{LiFePO}_{4}\right)$ that is one of the most interesting properties for batteries. On the other hand the low thermal expansion coefficient shows that it may be more advantageous to use this material in certain temperature conditions.

Finally we can conclude that we have achieved an electronic ceramic using very low cost products with interesting electrical and physical properties which could improve the batteries performances.

Advanced studies are in progress with other physico-chemical analysis to determine a quantitative composition of this material.

\section{Acknowledgments}

Financial support of the Senegalese Ministry High Education and Research and the West African Economic and Monetary Union (WAEMU) are gratefully acknowledged.

\section{References}

[1] Aimable, A., et al. (2006) Matériaux, 13, 1-9.

[2] Perea, A. (2011) Les phosphates de structure olive $\mathrm{LiMPO}_{4}(\mathrm{M}=\mathrm{Fe}, \mathrm{Co}, \mathrm{Mn})$ comme matériau actif d'électrode positive d'accumulateur Li-ion. Thesis, Université Montpellier II, Montpellier.

[3] Trad, K. (2010) Phosphates de fer de structures originales comme matériaux d'électrode positive pour batteries au lithium ou au sodium. Thesis, Université de Bordeaux 1, Bordeaux.

[4] Plancha, M.J., Rangel, C.M., Rodrigues, B. and Azevedo, F. (2010) Degradation of Lithium Iron Phosphate-Based Cathode in Lithium-Ion Batteries: A Post-Mortem Analysis. Eco community3 ${ }^{\circ}$ seminario Internacional Torres Vedas, 29-30 April 2010, Portugal.

[5] Julien, C.M., Zaghib, K., Mauger, A. and Groult, H. (2012) Advances in Chemical Engineering and Science, 2, 321329. http://dx.doi.org/10.4236/aces.2012.23037

[6] Adams, S. and Rao, R.P. (2010) Atom Indonesia, 36, 95-104.

[7] Johannes, M.D., Hoang, K., Allen, J.L. and Gaskell, K. (2012) Physical Review B, 85, Article ID: 115106. http://dx.doi.org/10.1103/PhysRevB.85.115106

[8] Maccario, M. (2007) Caractérisation de nanomatériaux C- $\mathrm{LiFePO}_{4}$ optimisés pour matériaux d'électrode positive pour batteries lithium-ion. Détermination du mécanisme de désintercalation/intercalation du lithium à partir de ces matériaux. Thesis, Université de Bordeaux 1, Bordeaux.

[9] Jonscher, A.K. (1967) Nature, 267, 673-679. http://dx.doi.org/10.1038/267673a0

[10] Klaus, F. (2013) Science and Technology of Advanced Materials, 14, Article ID: 043502. http://dx.doi.org/10.1088/1468-6996/14/4/043502

[11] Sidebottom, D.L. (1999) Physical Review Letters, 83, 983-986. http://dx.doi.org/10.1103/PhysRevLett.83.983 
Scientific Research Publishing (SCIRP) is one of the largest Open Access journal publishers. It is currently publishing more than 200 open access, online, peer-reviewed journals covering a wide range of academic disciplines. SCIRP serves the worldwide academic communities and contributes to the progress and application of science with its publication.

Other selected journals from SCIRP are listed as below. Submit your manuscript to us via either submit@scirp.org or Online Submission Portal.
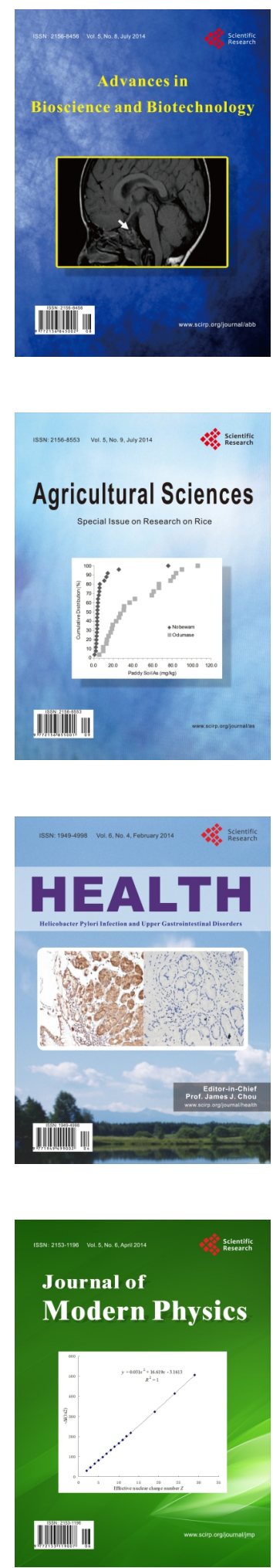
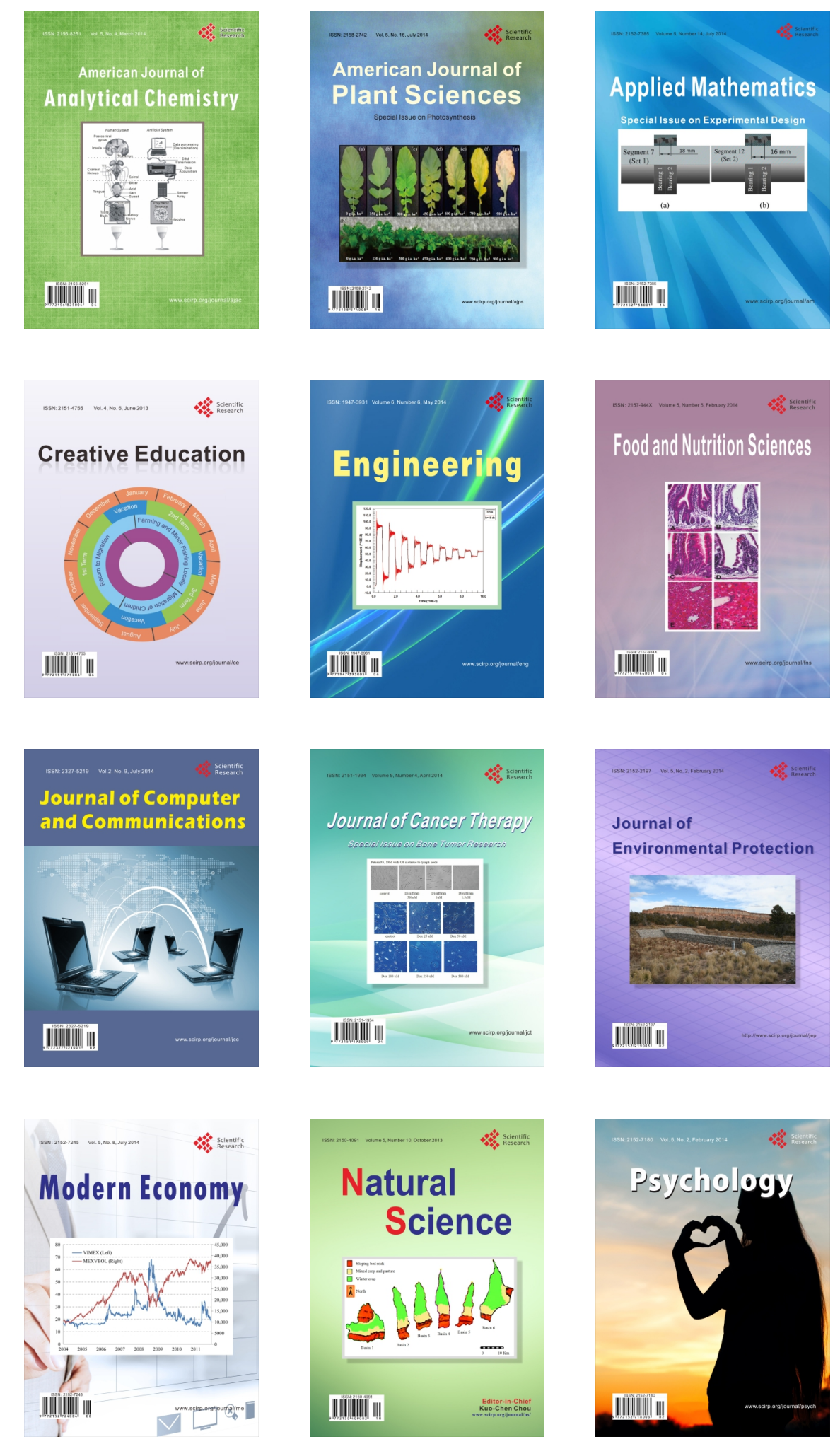